\title{
OCUPAÇÃO URBANA DA BACIA DO CÓRREGO DO VEADO EM PRESIDENTE PRUDENTE, SP
}

\author{
Andressa Mastroldi Ferrarezi ${ }^{1}$
}

\section{RESUMO}

A realidade das margens de corpos d'água das cidades brasileiras é, na maior parte das vezes, de descaso e degradação, mesmo quando as suas Áreas de Preservação Permanente (APP) encontramse desocupadas. A obrigatoriedade da sua preservação, após 1965, não garantiu, de fato, que fossem preservadas e que o curso d'água em área urbana pudesse se constituir como elemento da paisagem citadina. Este trabalho se propõe a realizar a análise morfológica das áreas de fundo de vale do Córrego do Veado em Presidente Prudente, confrontando o trecho canalizado, porém aberto e cuja ocupação se deu posteriormente a promulgação da Lei 4.771/65, e o trecho, já estudado, tamponado, anterior a 1965, com o objetivo de identificar os diversos tipos de tecidos urbanos existentes, verificando como as suas APPs foram tratadas e se há diferença do desenho urbano. O trabalho Justifica-se pela contribuição à discussão do modelo de ocupação destas áreas em cidades brasileiras e do seu planejamento, bem como de alternativas para futuras intervenções em áreas não ocupadas. $A$ partir do estudo sobre o crescimento da cidade, do seu traçado e parcelamento, da tipologia das edificações e das articulações entre estes.

PALAVRAS-CHAVE: Morfologia Urbana. Fundo de Vale. Área de Preservação Permanente.

\section{URBAN OCCUPANCY OF THE BASIN STREAM VEADO IN PRESIDENTE PRUDENTE, SP}

\section{ABSTRACT}

\footnotetext{
${ }_{1}^{1}$ Aluna de Graduação de Arquitetura e Urbanismo, FCT-UNESP. andressafz@hotmail.com.

${ }^{2}$ Possui Graduação em Arquitetura e Urbanismo pela USP-São Carlos (1996), Mestrado em Arquitetura e Urbanismo pela USP-São Carlos (2000) e Doutorado em Arquitetura e Urbanismo pela USP-FAU (2008), Docente - FCT-UNESP. arletefrancisco@fct.unesp.br.
} 
desenvolvimento urbano. Raramente, foram considerados como elementos paisagísticos incorporados ao desenho da cidade. Tiveram um papel mais utilitário, ou como receptáculo do que a sociedade descarta ou com a implantação de grandes avenidas e loteamentos. Nesse caso, os cursos d'água foram tratados como fundo de lote, lugar para onde não se volta o olhar.

Este trabalho tem o objetivo de verificar como ocorreu o processo de ocupação territorial das margens do Córrego do Veado em Presidente Prudente, após a promulgação da Lei 4.771/1965, confrontando com os resultados da primeira fase desta pesquisa, a qual estou a ocupação no córrego no período anterior a 1965. Recuperar a história do córrego, afim de compreender a dinâmica da área, aumentando a percepção da ocupação do recorte. Além de, contribuir para o debate sobre a urbanização dos fundos vales.

Na primeira etapa foi realizada uma revisão bibliográfica sobre o tema da morfologia urbana, dando continuidade às discussões realizadas na primeira fase desta pesquisa, e sobre o tema das APP e da legislação ambiental, sendo abordadas as seguintes leis: o Código Florestal e sua atualização (BRASIL, 1965); (BRASIL, 2012) e a Resolução CONAMA (BRASIL, 2002). Posteriormente, foi realizado um estudo sobre o crescimento da cidade de Presidente Prudente, partindo da bibliografia disponível - inicialmente SPOSITO (1995); SPOSITO (1990) - e a partir das plantas dos loteamentos disponíveis no site da Prefeitura Municipal de Presidente Prudente, verificando as datas de implantação, que teve como produto um mapa do crescimento da cidade, onde constatou-se a diferença temporal de implantação dos loteamentos entre os dois recortes estudados.

O estudo morfológico foi realizado por meio das análises da imagem orbital retirado do Google Earth $\AA$, dos mapas: Mapa de Presidente Prudente (Prefeitura Municipal de Presidente Prudente) e uma planta da cidade de 1977 (PMPP) e das plantas originais dos loteamentos obtidos pelo site da PMPP. Os dados foram sistematizados por meio de fichas (figura 01) de todos os dos loteamentos da área, os quais serviram para análise comparativa entre os traçados. 
As fichas se organizaram da seguinte maneira: Histórico do bairro retirado do texto "Expansão Territorial Urbana de Presidente Prudente" (SPOSITO, 1995); uma planta do bairro (site da PMPP) e dois cortes obtidos a partir do Google Earth $\AA$, localizados sempre em lugares estratégicos (avenidas e ruas principais ou próximas ao córrego); análises tipológicas das quadras e lotes; e, por fim, observações que analisam todas as informações descritas na ficha. Essas fichas têm o intuito de analisar e comparar os diferentes tipos de traçado da área de fundo de vale e identificar a lógica adotada no desenho urbano da área e sua relação com o córrego.

Figura 01: Modelo da Ficha realizada para cada Loteamento que cerca a área estudada.

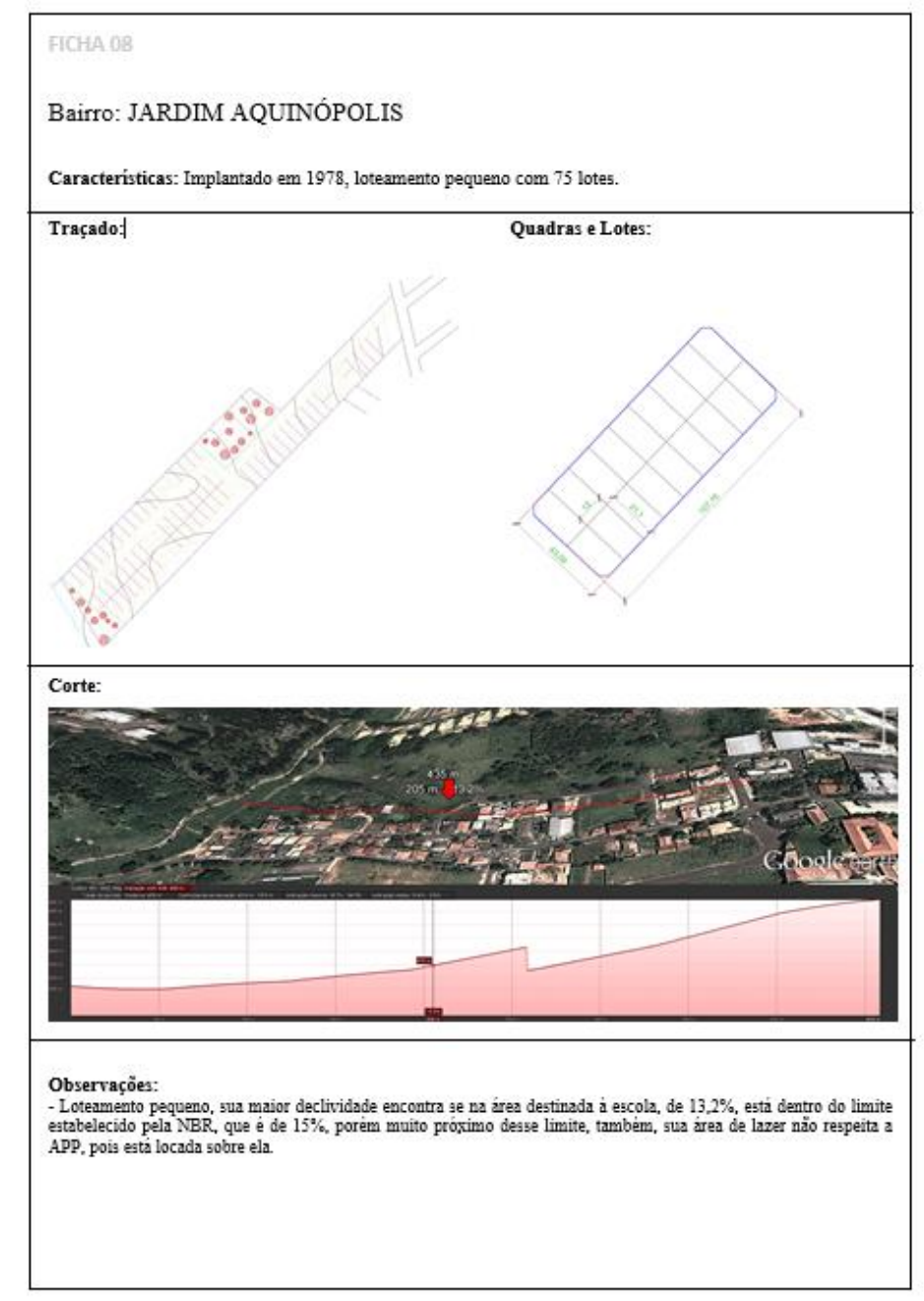

Fonte: Prefeitura Municipal de Presidente Prudente. Elaboração: SCATALON, A. P.; FERRAREZI, A. M 
A Morfologia Urbana é a ciência que estuda a forma, do ponto de vista urbanístico, e define-se como o estudo dos aspectos exteriores do meio urbano, por meio do qual se coloca em evidência a paisagem e sua estrutura. É, portanto, de acordo com a definição de Del Rio (1990), o estudo do "tecido urbano e seus elementos construídos formadores através de sua evolução, transformações, interrelações e dos processos sociais que os geram" (DEL RIO, 1990, p. 71).

MELLO (2007), afirma que a ausência de critérios de proteção dessas áreas acarreta sérios impactos ao meio ambiente: alteram substancialmente a dinâmica do curso d'água, provocam desequilíbrios como a intensificação de processos erosivos, de assoreamento do leito, inundação das margens e poluição hídrica. Identificam-se duas vertentes relativas ao modo de ver e atuar sobre os espaços às margens de rios e lagos. Na primeira, o corpo d'água é valorizado e incorporado à paisagem urbana, o que ocorre em geral com aqueles de maior porte. Na segunda vertente, os corpos d'água são desconsiderados, são subprodutos urbanos; a cidade fica de costas para os espaços das margens, que viram espaços degradados, depósitos de lixo; muito frequentemente os leitos são canalizados ou simplesmente aterrados. É essa segunda vertente que pode ser observada em Presidente Prudente.

Em 1965, é aprovada a lei federal (Lei 4.771/65) que rege sobre os cursos d'águas e suas APPs, que define a faixa de APP como cinco metros. A partir de então, a dimensão desta sofre várias alterações, (figura 02). Considerando a dimensão do Córrego do Veado, em 1979, a faixa de APP passa a ser de quinze metros, pela Lei de Parcelamento do Solo (Lei 6.766/79), depois para trinta metros, segundo a Lei 7511/86 (alteração do Cód. Florestal). No Cód. Florestal atual (Lei 12.651/12), o dimensionamento continuou o mesmo, mudando, o ponto a partir de onde é medida: em 1965 a medida foi definida a partir do leito de cheia, agora passa a ser medida a partir do leito regular. Essa alteração é bastante expressiva, pois, em alguns casos, a diferença entre o leito de cheia e o regular é maior que a própria APP.

Figura 02. Evolução da dimensão da APP Urbana, de acordo com a dimensão do Córrego do Veado. 

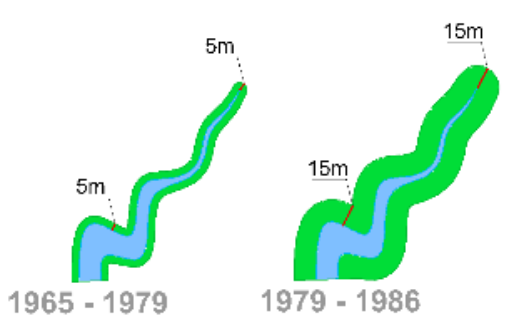
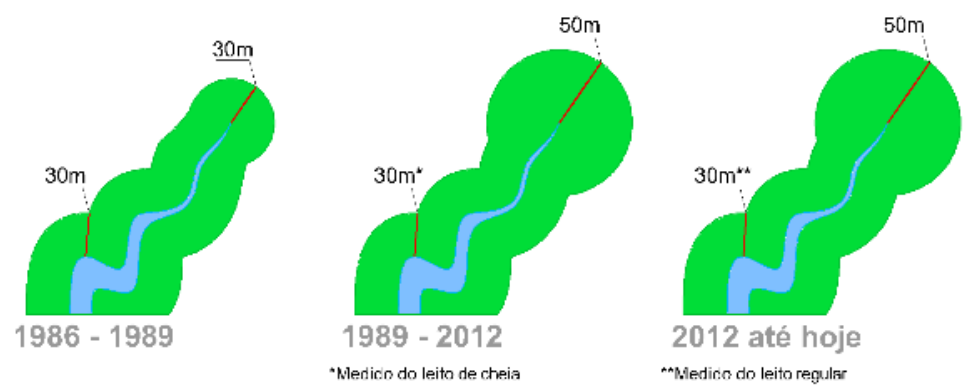

Fonte: Lei 4.771/65, Lei 6.766/79, Lei 7511/86 e Lei 12.651/12. Elaborado pela Autora

A definição de Área de Preservação Permanente foi estabelecida pela Lei 4.771/65 (Código Florestal) e ratificada pela Lei oㅜ 12.651/12 no art. 3o, inciso II é estabelecida como:

Área protegida, coberta ou não por vegetação nativa, com a função ambiental de preservar os recursos hídricos, a paisagem, a estabilidade geológica e a biodiversidade, facilitar o fluxo gênico de fauna e flora, proteger o solo e assegurar o bem-estar das populações humanas. (Lei 4.771/65)

Com a expansão das cidades e o crescimento econômico e demográfico, o meio urbano e o meio ambiente competem pelo mesmo espaço, gerando prejuízo de ambos os lados. Com isso ocorrem ocupações irregulares, aberturas de vias e equipamentos urbanos em APP, gerando enchentes, perda na qualidade da água, assoreamento dos corpos hídricos e destruição da fauna e flora local, ações que prejudicam o bem-estar dos moradores da própria cidade.

A área analisada na primeira parte da pesquisa (fig. 03) apresentava 0 Córrego do Veado, incialmente, como barreira. Porém, com o Projeto do Parque do Povo, passou a ser um atrativo, fazendo com que sua ocupação se estendesse em todo entorno do córrego. Já a segunda área (fig. 03) é constituída por muitos vazios e por interrupções no desenho urbano, causados ou pelas ramificações dos córregos, gerando mais áreas de APP, as quais não podem ser ocupadas, ou, por alguns outros obstáculos como: os dois frigoríficos, o cemitério, que além da desconexão com o tecido urbano, são considerados insalubres; a rodovia como uma barreira física para a conexão; e o próprio relevo, que gera dificuldade na ocupação e nas continuidades, já 


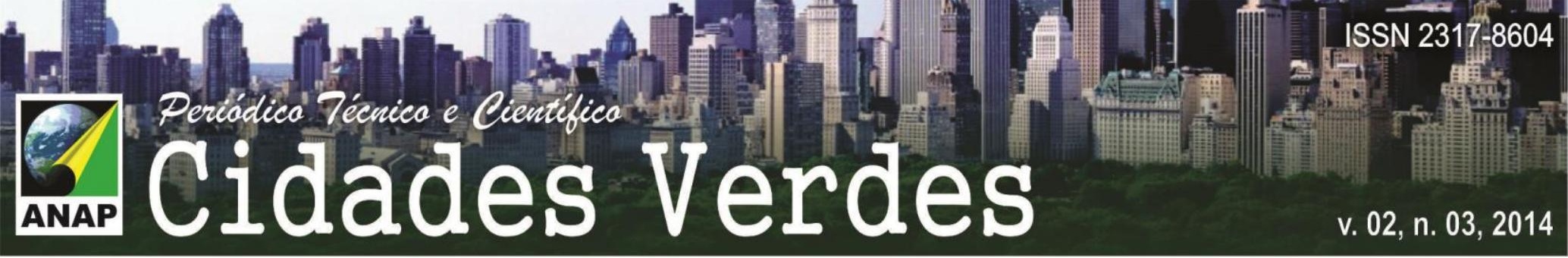

concentrando as áreas verdes e institucionais nas adjacências das áreas de preservação, ou seja, apesar das mudanças na legislação essas áreas ainda não têm o tratamento adequado enquanto elemento natural e estruturador da paisagem urbana.

Figura 04. Crescimento de Presidente Prudente.

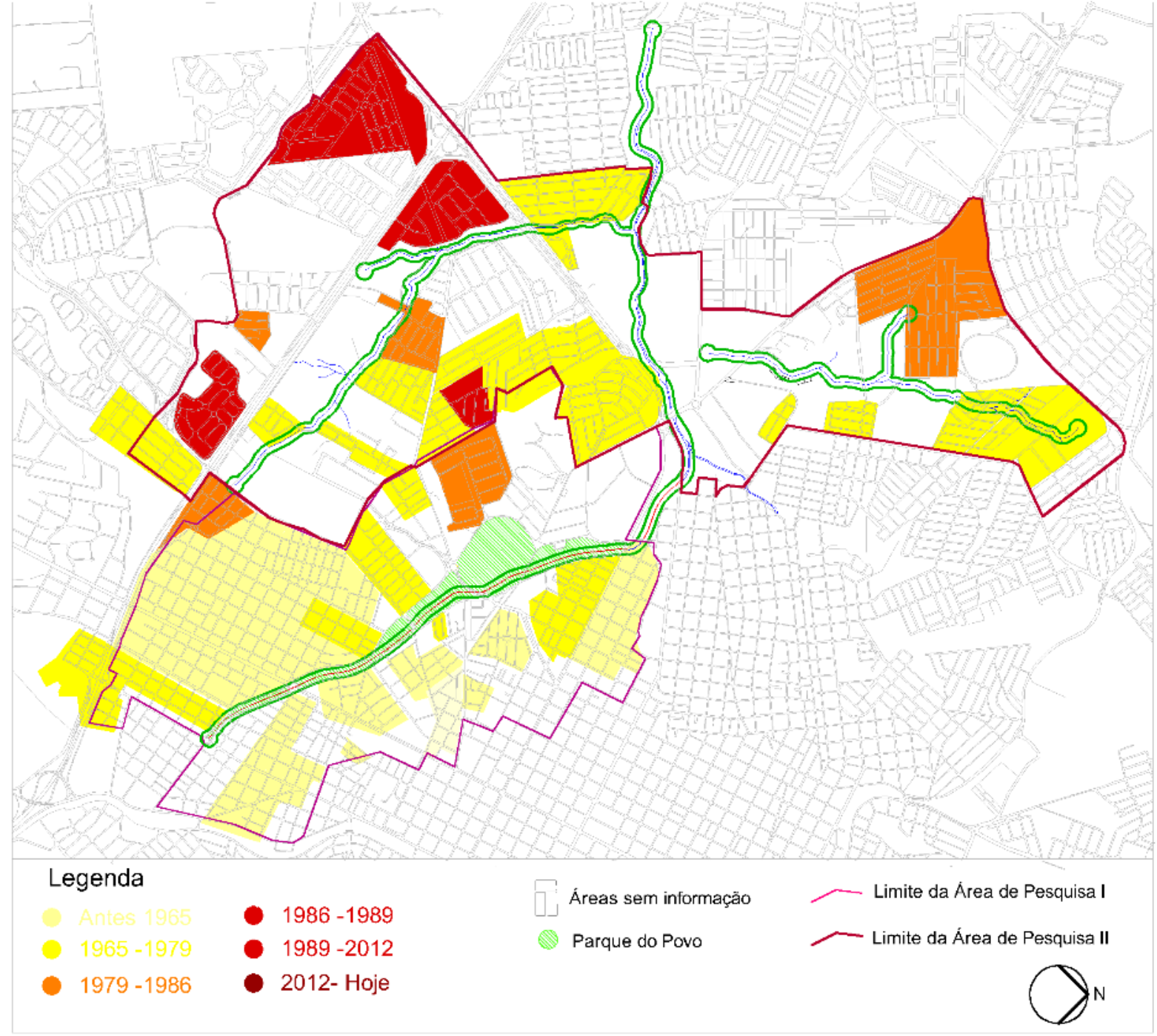

Fonte: SPOSITO (1990), SPOSITO (1995), PMPP.

Analisando as APPs, no trecho próximo à nascente, na área $\mathrm{I}$, e em alguns trechos na área II, há ocupações nessas áreas, porém os loteamentos foram implantados anteriores a 1986, quando não havia legislação referente à preservação 
das margens dos corpos hídricos ou quando era de no máximo quinze metros, portanto quando houve as ocupações, estas foram regulares e por isso ainda continuam regulares. Referente a isso ainda, foi constatado a maioria das nascentes está em nessas condições, pois elas só passaram a ser protegidas com um raio de cinquenta metros a partir de 1989.

A partir das análises das fichas dos loteamentos e suas sínteses, observa-se como ocorreu o crescimento de Presidente Prudente, ignorando a presença do Córrego do Veado, porém no primeiro recorte o traçado deu costas a este, já no segundo recorte as APPs são consideradas "sobras" dos loteamentos e usadas como área verde ou de lazer. Observa-se que, nas proximidades das grandes avenidas, 0 traçado é regular, semelhante ao "tabuleiro de xadrez" do núcleo central da cidade e, quando algum obstáculo se aproxima, tais como o córrego ou relevo acentuado, o traçado passa a ser irregular. Porém, não foram identificadas características comuns entre eles, isto é, alguma coerência, além disso, o desenho não tira o melhor proveito da topografia.

\section{CONCLUSÃO}

Considerando a situação de negação dos córregos na maioria dos meios urbanos, conclui-se que na primeira parte do Córrego do Veado, apesar de ter sido canalizado e tamponado, boa parte de sua APP foi conservada com a implantação de um parque linear ao longo do córrego, o Parque do Povo. Já na segunda parte, uma porção da APP foi ocupada por construções, ruas e avenidas e outra se mantém conservada. Ou seja, na primeira parte do projeto, boa parte dos loteamentos foi implantada anteriormente a 1965, ano de aprovação do Código Florestal, que não havia grandes preocupações com as áreas de preservação permanente. Porém, na segunda, o bairro mais antigo é datado de 1966, posterior ao Código Florestal, com isso observa-se uma preocupação maior com as áreas de preservação nesta etapa do projeto. 
Contudo, o "não olhar" para estas áreas persiste até hoje. Os córregos ainda são vistos como barreiras para a ocupação territorial e, juntamente com as áreas verdes e institucionais dos loteamentos, são apenas poupados pela legislação, mas não incorporados ao desenho urbano, apesar da preservação das funções das APPs, na área II desta pesquisa.

\section{REFERÊNCIAS}

BRASIL. Código Florestal, Lei 12.651, de 25 de maio de 2012.

BRASIL. Código Florestal. Lei no. 4771, 15 de Agosto de 1965.

BRASIL. Estatuto da Cidade. Lei 10.257, 10 de julho de 2001.

BRASIL. Lei de Parcelamento Territorial Urbano. Lei nº 6.766, 19 de dezembro de 1979.

CONAMA, Resolução № 302, 20 de março de 2002.

DEL RIO, V. Introdução ao desenho urbano no processo de planejamento. São Paulo: Pini, 1990

MELLO, S. S. Áreas De Preservação Permanente Em Margens De Corpos D’água Urbanos: Princípios De Intervenção E Subsídios À Construção Do Marco Legal. In: Seminário Nacional sobe Áreas de Preservação Permanente em Meio Urbano, I, 2007, São Paulo. Anais... São Paulo: Universidade de São Paulo, 2007.

SPOSITO, E. S. Produção e apropriação da renda fundiária urbana em Presidente Prudente, Presidente Prudente, 1990. Dissertação (Tese de Doutorado) - Presidente Prudente, Faculdade de Ciência e Tecnologia, Universidade Estadual Paulista “Júlio de Mesquita Filho", Presidente Prudente, 1990

SPOSITO, M. E, B. Expansão Territorial Urbana de Presidente Prudente. Revista Recorte GAsPERR, №4. 1995. 